\title{
Influence of the frontal joint of the bitumen sheet on the final strength of the joint
}

\author{
Jan Plachý' ${ }^{1, *}$, Jana Vysoká ${ }^{1}$, and Radek Vejmelka ${ }^{1}$ \\ ${ }^{1}$ Vysoká škola technická a ekonomická v Českých Budějovicích, Okružní 10, 37001 České \\ Budějovice
}

\begin{abstract}
This article focuses on the frequently discussed topic how to make the frontal joints of bitumen sheets with coarse-grained surface coating. Bitumen sheets have a spill in the place of these joints. Insufficient strength of the frontal joint is one of the possible faults in waterproofing using bitumen sheets. The paper compares different ways of performing these joints in terms of force stress based on surface treatment. Surface treatment is possible by immersing the sprinkle, scraping it into the bitumen sheet mass, or simply heating the surface and leaving it unpainted.
\end{abstract}

\section{Introduction}

One of the frequent failures that arise on the roof cladding is the release of bitumen sheets in joints. Bitumen sheets joints can be divided into longitudinal (lateral) or transverse (front). See Figure 1.

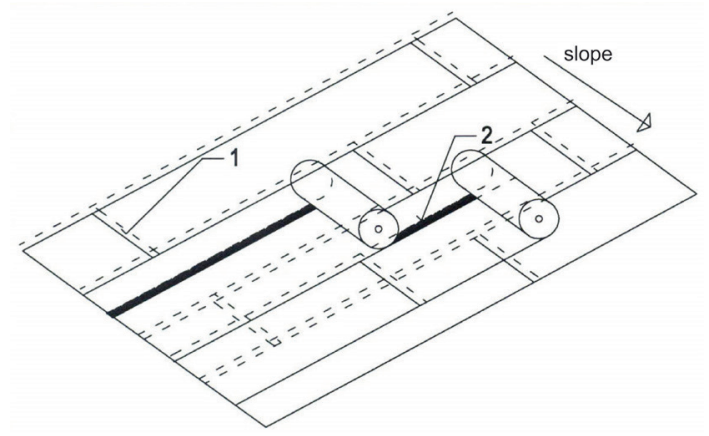

Fig. 1. Types and nomenclature of joints of bitumen sheets (1 - frontal, transverse, 2 - lateral, longitudinal) [1].

In the case of single-liner systems, bitumen sheets with coarse-grained spreading are used as the final liner of the waterproofing liner. For better execution of the joints, bitumen sheets with coarse grain on the upper surface are connected at the lateral joint site with polymeric tape connections. Sprinkle is omitted here. At the site of the frontal joint of these bitumen sheets sprinkle is left, there is no strip without surface treatment. See Figure 2.

\footnotetext{
* Corresponding author: plachy@mail.vstecb.cz
} 


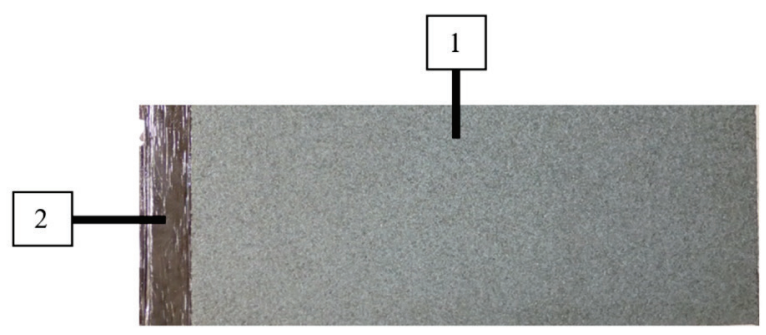

Fig. 2. Bitumen sheet (1 - frontal, transverse, 2 - side, longitudinal). Source: author.

One of the problems involved in the practical implementation of coarse-grained bitumen sheets joints is the question of how the respective surface treatment of the sheet will affect the resulting joint strength. The problem of bitumen sheets has been dealt with [1-5], the topic of adhesion to bitumen cover is described in [6]. The surface treatment of the coarsegrained bitumen sheets prior to the actual construction of the transverse joint, only [2] dealt with it. The author states that when coarse-grained sprinkle is spattered, it occurs a $5-10 \%$ increase of shear strength [7], comparing to non-spattered, depending on the type of bitumen sheet.

In practice, it is possible to meet a total of three possible adaptations of the surface of the bitumen sheet and therefore this experiment was carried out. The first method is to heat the lower cheek of the upper sheet and the upper cheek of the lower sheet. This is a classic, commonly performed method. The second option is to spatter the lower sheet at the joining point and the third option is to immerse the bottom sheet into the mass of the bitumen sheet, see Figure 3
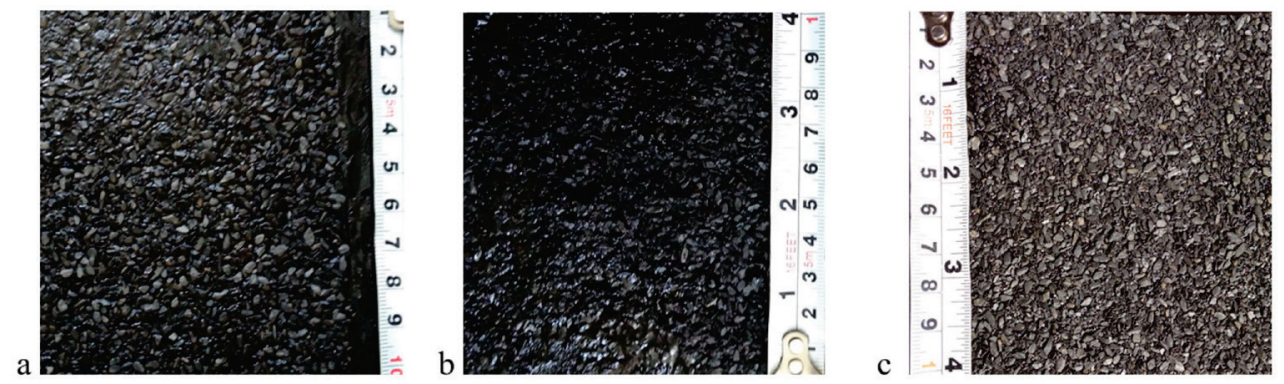

Fig. 3. Modification of the frontal (transverse) connection of the bitumen sheet. a - immersion of the lower sheet, $\mathrm{b}$ - sprinkle is spattered, $\mathrm{c}$ - warming of the lower cheek of the upper sheet and the upper cheek of the lower sheet. Source: author.

A - Immersion of the lower sheet sprinkle into the mass of the bitumen sheet. When this treatment is carried out, the asphalt mixture, upon burning the bitumen sheet, exits to the surface and forms more than $50 \%$ of the surface of the sheet. In the case of bitumen sheet with a polyester carrier liner (PES), this carrier liner is damaged by the increased temperature. See Figure 3a.

B - Spattering the bitumen sheet by means of an insulating spoon. The adjustment consists in heating the surface of the heat with a burner and the sealing, using specially treated spoon, of sprinkle into asphalt. There is a risk of the liner being exposed, which can cause problems in smelting the upper sheet. See Figure $3 b$.

$\mathrm{C}$ - Fomenting the lower cheek of the upper bitumen sheet and the upper cheek of the lower bitumen sheet (the classic method). With this option, the asphalt mixes up to about $20 \%$ after heating. See Figure 3c. 
The strength of the joint [7] affects the type and thickness of the bituminous cover material of the bitumen sheet, the adhesion between the support liner and the bitumen cover, the adhesion between the coarse-grained sprinkle and the bitumen cover, and the type of the bitumen sheet carrier liner.

It is possible to say the hypothesis that, according to theoretical assumptions, the highest strength should have a connection where the immersion in the bitumen mass is immersed. In this variant, $\mathrm{A}$ is the largest contact surface in combination with bitumen mass - bitumen mass. In the case of variant $\mathrm{B}$ - the lower bitumen sheet sprinkle spattering and variant $\mathrm{C}$ - fomenting of the lower cheek of the upper bitumen sheet and the upper cheek of the lower bitumen sheet as a result of the smaller contact surface in the bitumen mix - bitumen mix, the resulting joint strength should be less than that of variant A. Another important factor that affects the properties of the joint is the skill of the worker who performs the joint. The surface treatment of the bitumen sheet at the joint site by immersing and spattering was compared with the conventional embodiment.

\section{Material and methods of testing}

\subsection{Materials}

For the tests, a $5.2 \mathrm{~mm}$ thick bitumen sheet was selected with cover mass of modified copolymer styrene - butadiene - styrene (SBS), carrier liner of polyester fleece (PY) weighing $230 \mathrm{~g} / \mathrm{m}^{2}$ and the slate slivers sprinkle. The lengths of the transverse joint (W) were determined on the basis of [1] in two variants of $120 \mathrm{~mm}$ and $150 \mathrm{~mm}$. In total, six samples were prepared.

\subsection{Methods of testing}

For each variant of the joint surface treatment, nine test bodies were always prepared. An increase in the number of test bodies out of five, which is prescribed [7], has been done for statistical evaluation. Calculations were performed with precision to two decimal places. Tests were performed at $(23 \pm 2){ }^{\circ} \mathrm{C}$. The test procedure was performed according to [7]. For the test scheme, see Figure 4.

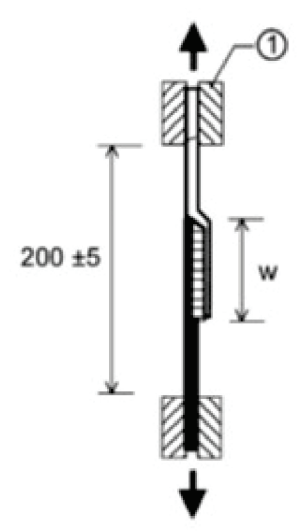

Fig. 4. Diagram of the joint shearing resistance test in accordance with ČSN EN 12317-1. W - joint size. Source: author. 


\subsection{Evalution}

Nine test samples of the determined combinations were used for testing. The final force is presented in the form $\bar{x} \pm \bar{\vartheta}(\bar{x})$, where $\bar{x}$ is the arithmetic average and $\bar{\vartheta}(\bar{x})$ is the probable measurement error. The latter was determined on the basis of the error theory for deviations in the arithmetic average using the formula:

$$
\bar{\vartheta}(\bar{x})=\frac{2}{3} \sqrt{\frac{1}{n(n-1)} \sum_{i=1}^{n}\left(x_{i}-\bar{x}\right)^{2}} .
$$

\section{Results}

The measurement results and estimates of standard deviations are nearly the same for each frontal joint size. The $150 \mathrm{~mm}$ front link strength was higher than $120 \mathrm{~mm}$ in length. A summary of the individual measurement results is summarized in Table 1.

Table 1. Shear strength of the frontal joint of the bitumen sheet with various sheet surface treatments. Source: author.

\begin{tabular}{|l|c|c|c|c|c|c|}
\hline \multirow{2}{*}{ Samples } & \multicolumn{5}{|c|}{ Shear strength of the frontal joint [kN/m] } \\
\cline { 2 - 7 } & \multicolumn{3}{|c|}{ Joint width 120 mm } & \multicolumn{2}{c|}{ Joint width 150 mm } \\
\cline { 2 - 7 } & $\begin{array}{c}\text { Sprinkle } \\
\text { immersed }\end{array}$ & $\begin{array}{c}\text { Classic } \\
\text { treatment }\end{array}$ & $\begin{array}{c}\text { Sprinkle } \\
\text { spattered }\end{array}$ & $\begin{array}{c}\text { Sprinkle } \\
\text { immersed }\end{array}$ & $\begin{array}{c}\text { Classic } \\
\text { treatment }\end{array}$ & $\begin{array}{c}\text { Sprinkle } \\
\text { spattered }\end{array}$ \\
\hline $\begin{array}{l}\text { The mean value } \\
{[\mathbf{k N / m}]}\end{array}$ & 18.64 & 19.11 & 18.96 & 19.48 & 19.64 & 19.26 \\
\hline $\begin{array}{l}\text { Probable error } \\
{[\mathbf{k N} / \mathbf{m}]}\end{array}$ & 0.69 & 0.67 & 0.88 & 0.65 & 1.22 & 1.40 \\
\hline $\begin{array}{l}\text { Standard deviation } \\
{[\mathbf{k N} / \mathbf{m}]}\end{array}$ & 1.54 & 1.59 & 1.52 & 1.13 & 1.49 & 1.71 \\
\hline $\begin{array}{l}\text { Coefficient of } \\
\text { variation [ \%] }\end{array}$ & 8.25 & 8.30 & 8.03 & 5.82 & 7.60 & 8.89 \\
\hline
\end{tabular}

\section{Discussion}

The original hypothesis of increasing the strength of the frontal joint in the immersed sprinkle was not confirmed. The effect of the higher percentage of bitumen mass on the surface of the bitumen sheet is therefore not a decisive factor. The effect of the higher percentage of bitumen mass on the surface of the bitumen sheet is therefore not a decisive factor. In the results, it is interesting to note that for both sizes of joints, greater strength was achieved in the classic design of the front joint of the sheet.

On the basis of these measurements, it can be stated that the impact of spattering (sprinkle push off) and immersing of the sheet has no significant influence on the shear joint strength in terms of the lacerated load of the joint. Individual measurements and estimates of standard deviations were comparable. The question of the implementation of the frontal joints remains open and may be the subject of further testing and research 


\section{Conclusion}

The results of the experimental measurement showed that with the correct implementation technology the difference in shear strength is very small. It is not necessary to perform the surface treatment at the location of the frontal joints by spattering and immersing the sprinkle. These adjustments are, on the contrary, risky in terms of possible damage to the carrier liner. In the case of bitumen sheets, which are used as the final one in the waterproofing strata, and in the case of single-liner applications, polyester is used.

\section{References}

1. J. Plachý, Bitumen sheet joints under the influence of temperature and time in the composition of single-membrane roofs (Brno University of Technology, Faculty of civil engineering, Brno, 2005)

2. R. Šmehyl, Stability of joints of bitumen membranes (University of Technology in Bratislava, Faculty of civil engineering, Bratislava, 2007)

3. T. Petř́iček, P. Kacálek, R. Smolka, AMR 1041, 71-74 (2014)

4. T. Petříček, P. Kacálek, T. Hlavačka, MATEC Web of Conf. 93, 03007 (2017)

5. J. Plachý, MATEC Web of Conf. 93, 02006 (2017)

6. J.A. Marques, J. G. Lopes, J. R. Correia, Construction and Building Materials 25(1), 138-144 (2011)

7. ČSN EN12317-1 Flexible sheets for waterproofing - Part 1: Bitumen sheets for roof waterproofing - Determination of shear resistance of joints (Prague, 2000) 
